\title{
Laboratory assessment of the direct oral anticoagulants: who can benefit?
}

\author{
Imo J Akpan', Adam Cuker²
}

'Division of Hematology/Oncology, Department of Medicine, Columbia University Irving Medical Center, New York, NY, United States 2Department of Medicine and Department of Pathology \& Laboratory Medicine, Perelman School of Medicine at the University of Pennsylvania, Philadelphia, PA, United States

\author{
Correspondence to: \\ Adam Cuker, MD, MS, \\ Hospital of the University of \\ Pennsylvania, \\ 3400 Spruce Street, \\ Philadelphia, PA 19104, USA, \\ phone: +1 (215) 615-6555, \\ e-mail: adam.cuker@ \\ pennmedicine.upenn.edu \\ Copyright by the Author(s), \\ 2021 \\ Kardiol Pol. 2021 \\ 79 (6): 622-630; \\ DOI: 10.33963/KP.a2021.0021 \\ Received: \\ April 28, 2021 \\ Revision accepted: \\ May 22, 2021 \\ Published online: \\ May 24, 2021
}

\begin{abstract}
A B S TR A C T
Direct oral anticoagulants (DOACs), apixaban, dabigatran, edoxaban, and rivaroxaban, are widely used for the prevention of stroke and systemic embolism in patients with non-valvular atrial fibrillation as well as for prevention and treatment of venous thromboembolism. Although DOACs do not require routine laboratory monitoring of anticoagulant effect, there are special situations in which laboratory assessment may be warranted. Laboratory tests include quantitative assays, which measure plasma DOAC levels, and qualitative or semi-quantitative assays, which may be used to screen for the presence of clinically relevant DOAC levels. Indications for laboratory assessment include emergent indications (serious bleeding, urgent surgery, acute ischemic stroke with consideration of thrombolysis) and elective indications (extremes of bodyweight, renal hypo- or hyperfunction, liver disease, suspected drug-drug interactions, suspected gastrointestinal malabsorption). In general, quantitative assays that measure DOAC levels may be used for elective indications, whereas screening assays may be necessary for emergent indications if a quantitative assay with sufficiently rapid turnaround time is not available. Therapeutic ranges for DOACs have not been defined. In lieu of therapeutic ranges, data from pharmacokinetic studies may be used to determine whether a patient's plasma DOAC level falls within the expected range. If it does not, a change in therapy may be warranted. Depending on the clinical scenario, a change in therapy may involve adjustment of the DOAC dose, a change to a different DOAC, or a change to a different class of anticoagulant.
\end{abstract}

Key words: apixaban, dabigatran, edoxaban, laboratory measurement, rivaroxaban

Kardiol Pol 2021; 79, 6: 622-630

\section{INTRODUCTION}

Direct oral anticoagulant (DOAC) use has now outpaced vitamin $\mathrm{K}$ antagonists (VKAs) for various indications including non-valvular atrial fibrillation and treatment and prevention of venous thromboembolism (VTE) [1, 2]. There are four DOACs approved by the US Food and Drug Administration (FDA) that are available in the US, Europe, and other jurisdictions including the direct thrombin inhibitor, dabigatran, and the direct oral factor Xa inhibitors, rivaroxaban, apixaban, and edoxaban. The properties of these agents are summarized in Table 1.

DOACs have several advantages compared with VKAs. They are associated with lower risk of major bleeding including intracranial hemorrhage [3-7]. They also have a shorter half-life, quicker onset of action, and fewer dietary and drug-drug interactions [8, 9]. An additional advantage of DOACs is that they do not require routine laboratory monitoring of anticoagulant effect because they have a broad therapeutic window and more predictable pharmacokinetics than VKAs. Nevertheless, there are special situations in which DOAC laboratory assessment may be warranted. In this review, we discuss laboratory assays for DOAC assessment and their interpretation. We also describe circumstances in which such testing is warranted and how the results may be used to guide management.

\section{LABORATORY ASSAYS FOR DOAC ASSESSMENT}

Laboratory assays for DOAC assessment can be divided into quantitative tests used to measure plasma drug levels and qualitative or semi-quantitative tests used to screen for the presence of clinically relevant drug levels (Table 2). 
Table 1. Properties of direct oral anticoagulants

\begin{tabular}{|c|c|c|c|c|}
\hline & Dabigatran & Rivaroxaban & Apixaban & Edoxaban \\
\hline References & {$[46,47]$} & {$[48,49]$} & {$[50]$} & {$[51]$} \\
\hline Mechanism of action & Thrombin inhibitor & Factor Xa inhibitor & Factor Xa inhibitor & Factor Xa inhibitor \\
\hline Bioavailability, \% & 3 & $80-100$ (when taken with food) & 50 & 62 \\
\hline Time to peak, hour & $1-2$ & $2-4$ & $3-4$ & $1-2$ \\
\hline Protein binding, \% & 35 & $92-95$ & 87 & 55 \\
\hline $\begin{array}{l}\text { Half-life (normal renal } \\
\text { function), hour }\end{array}$ & $12-14$ & $5-9$ & 12 & $10-14$ \\
\hline Metabolizers & Major substrate of P-gp & $\begin{array}{l}\text { Major substrate of CYP3A4. } \\
\text { Minor substrate of P-gp }\end{array}$ & $\begin{array}{l}\text { Major substrate of CYP3A4. } \\
\text { Minor substrate of P-gp }\end{array}$ & Major substrate of P-gp \\
\hline Renal elimination, $\%$ & $\sim 80$ & $\sim 66$ & $\sim 27$ & $\sim 50$ \\
\hline
\end{tabular}

Abbreviations: CYP, cytochrome P450; P-gp, P-glycoprotein

Table 2. Laboratory assays for direct oral anticoagulants

\begin{tabular}{l|cc} 
& Dabigatran & Rivaroxaban, Apixaban, Edoxaban \\
\hline Quantitative assays for measurement of drug & LC-MS/MS & LC-MS/MS \\
levels & dTT & Chromogenic anti-Xa assay calibrated with drug of interest \\
& ECT & Chromogenic heparin anti-Xa assay $^{\mathrm{d}}$ \\
Screening assays for excluding the presence of & ECA & DOASENSE $^{\mathrm{TMc}}$ \\
clinically significant drug levels ${ }^{\mathrm{a}}$ & TT $^{\mathrm{b}}$ & DOASENSE $^{\mathrm{TMC}}$ \\
\hline
\end{tabular}

a"Clinically significant drug levels" refers to DOAC levels that may contribute to bleeding risk. The minimum DOAC level that may contribute to bleeding risk is unknown. The International Society on Thrombosis and Haemostasis suggests consideration of DOAC reversal in patients with serious bleeding and a DOAC level $>50 \mathrm{ng} / \mathrm{ml}$ and in patients undergoing a surgical procedure with high bleeding risk and a DOAC level $>30 \mathrm{ng} / \mathrm{ml}$. ${ }^{\mathrm{b}} \mathrm{A}$ normal TT excludes the presence of clinically significant dabigatran levels. A prolonged TT may suggest the presence of clinically significant or trivial levels of dabigatran. ${ }^{\mathrm{C}} \mathrm{A}$ negative DOASENSE ${ }^{\mathrm{TM}}$ generally excludes the presence of clinically significant DOAC levels. A positive DOASENSE ${ }^{T M}$ may suggest the presence of clinically significant or trivial DOAC levels. ${ }^{\mathrm{A} A}$ chromogenic heparin anti-Xa assay below the lower limit of quantitation generally excludes the presence of clinically significant levels of rivaroxaban, apixaban, or edoxaban.

Abbreviations: DOAC, direct oral anticoagulants; dTT, dilute thrombin time; ECA, ecarin chromogenic assay; ECT, ecarin clotting time; LC-MS/MS, liquid chromatography-tandem mass spectrometry; TT, thrombin time

\section{Assays for measuring drug levels}

Liquid chromatography with tandem mass spectrometry (LC-MS/MS) is the gold standard for measuring DOAC levels. However, it is not widely available in clinical practice, particularly when rapid turnaround is required $[10,11]$.To meet the need for more rapid provision of results, simpler assays with greater availability have been developed for the measurement of dabigatran and direct oral factor Xa inhibitors that demonstrate close correlation with LC-MS/MS (Table 2).

\section{Dabigatran}

When the dilute thrombin time (dTT) is used in conjunction with a drug calibrator, there is a strong linear relationship between dabigatran levels across a wide range of concentrations with less accuracy at levels $<50-100 \mathrm{ng} / \mathrm{ml}$ [10-12]. Ecarin is a metalloprotease from the venom of the sawscaled viper (Echis carinatus) that cleaves prothrombin to the intermediate product meizothrombin, which is inhibited by dabigatran [10-12]. Ecarin-based assays including the ecarin clotting time (ECT) and ecarin chromogenic assay (ECA) demonstrate a strong linear correlation across a wide range of dabigatran concentrations with reduced accuracy at levels $<50 \mathrm{ng} / \mathrm{ml}$ and $>500 \mathrm{ng} / \mathrm{ml}[10,12]$.

\section{Oral factor Xa inhibitors (rivaroxaban, apixaban, edoxaban)}

For measurement of rivaroxaban, apixaban, and edoxaban, chromogenic anti-Xa assays calibrated with the drug of interest show a linear correlation across a wide range of concentrations. However, the correlation is less precise at lower drug levels (rivaroxaban level $<30 \mathrm{ng} / \mathrm{ml}$, apixaban $<15 \mathrm{ng} / \mathrm{ml}$, edoxaban $<10 \mathrm{ng} / \mathrm{ml}$ ) and at levels $>500 \mathrm{ng} / \mathrm{ml}$ [10-12].

\section{Screening assays to determine whether clinically relevant drug levels are present}

In many centers, assays for DOAC quantitation may not be available, particularly on a 24/7 basis. When such assays are not available, qualitative or semi-quantitative assays, which are more readily accessible, may be used to screen for the presence of clinically relevant drug levels (Table 2).

\section{Dabigatran}

The thrombin time (TT) is widely available and is exquisitely sensitive to even minor, clinically insignificant concentrations of dabigatran. Therefore, a normal TT excludes the presence of clinically significant levels of dabigatran, whereas a prolonged TT may indicate the presence of clinically significant or trivial levels of drug [13]. DOASENSE ${ }^{T M}$ is a urine dipstick that provides a rapid qualitative assessment of the presence of dabigatran and is only available in Europe [11,14]. Like the TT, a negative dipstick generally excludes the presence of clinically significant plasma drug levels but a positive result cannot distinguish between clinically relevant and trivial plasma levels of dabigatran. 
Table 3. Expected steady-state peak and trough direct oral anticoagulants (DOAC) concentrations

\begin{tabular}{|c|c|c|c|c|}
\hline DOAC & Dose & $\begin{array}{c}\text { Peak (ng/ml) } \\
5^{\text {th }}-95^{\text {th }} \text { percentile }\end{array}$ & $\begin{array}{c}\text { Trough (ng/ml) } \\
5^{\text {th }}-95^{\text {th }} \text { percentile }\end{array}$ & References \\
\hline Dabigatran & $150 \mathrm{mg}$ bid & $64-443^{a}$ & $31-225^{a}$ & {$[52,53,54]$} \\
\hline Rivaroxaban & $2.5 \mathrm{mg}$ bid & $28-70^{\mathrm{b}}$ & $6-37^{b}$ & {$[48]$} \\
\hline Rivaroxaban & 20 mg daily & $184-343^{a}$ & $12-137^{a}$ & {$[53,55]$} \\
\hline Apixaban & $5 \mathrm{mg}$ bid & $69-321^{a}$ & $34-230^{\mathrm{a}}$ & {$[53,56]$} \\
\hline Edoxaban & 60 mg daily & $91-321^{\mathrm{a}}$ & $31-230^{\mathrm{a}}$ & {$[53,57]$} \\
\hline
\end{tabular}

Adapted from Hindricks et al. [53].

an patients taking a DOAC for atrial fibrillation. ${ }^{b}$ In patients taking a DOAC for secondary prevention of acute coronary syndromes

Oral factor Xa inhibitors (rivaroxaban, apixaban, edoxaban)

Chromogenic anti-Xa assays calibrated with heparin show less linearity and are therefore not suitable for quantification of oral factor Xa inhibitors. However, a heparin anti-Xa level below the lower limit of quantitation is generally sufficient to exclude clinically relevant drug levels $[10,11]$. As with dabigatran, DOASENSE'" can be used to screen for oral factor Xa inhibitors. A negative dipstick generally excludes the presence of clinically significant plasma drug levels whereas a positive result may indicate the presence of clinically relevant or trivial levels of oral factor Xa inhibitor.

\section{Prothrombin time and activated partial}

thromboplastin time

Dabigatran and the oral factor Xa inhibitors prolong the prothrombin time (PT) and activated partial thromboplastin time (APTT) in a dose-dependent manner. In general, the APTT is more sensitive to dabigatran and the PT is more sensitive to oral factor Xa inhibitors. Among oral factor Xa inhibitors, the PT and APTT are more sensitive to rivaroxaban and edoxaban than they are to apixaban. However, neither the PT nor APTT shows sufficient linearity to be suitable for DOAC quantitation. Moreover, the PT and APTT may remain normal in the presence of clinically relevant DOAC levels, depending on the sensitivity of the reagent [13]. Therefore, the PT and APTT cannot be relied upon as screening tests to exclude the presence of clinically significant drug levels.

\section{HOW TO INTERPRET DOAC LEVELS}

In order to interpret a DOAC level correctly, it is useful to know when the drug was last taken. When possible, a peak and trough level should be drawn because expected plasma drug levels have been defined for these time points (Table 3) [12]. However, there are situations in which it may be necessary to check a randomly timed level (e.g. in a patient with emergent bleeding) or in which it may not be possible to determine the time of last ingestion (e.g. in an unconscious patient).

Although several studies have demonstrated a relationship between DOAC levels and clinical outcomes [15], therapeutic ranges have not been defined for DOACs and a strategy of dose-adjustment to target certain drug levels has not been tested in clinical trials. In lieu of therapeutic ranges, it is useful to consider the expected steady-state peak and trough levels for a given DOAC at a given dose (Table 3), which are based on pharmacokinetic studies [10-12].

The minimal DOAC level that may contribute to bleeding is unknown. Guidance from the International Society on Thrombosis and Haemostasis (ISTH) suggests that reversal may be warranted in a bleeding patient with a level $>50 \mathrm{ng} / \mathrm{ml}$ or in a preoperative patient with a level $>30 \mathrm{ng} / \mathrm{ml}$, but it is important to emphasize that these thresholds are based on expert opinion rather than clinical evidence [16].

\section{INDICATIONS FOR LABORATORY ASSESSMENT OF DOACS}

Indications for laboratory assessment of DOACs may be divided into emergent and elective indications. Laboratory assessment for emergent indications must yield results within minutes in order to inform management decisions. At many centers, assays that measure DOAC levels are not available with such a short turnaround time and the clinician must rely on screening assays (Table 2). Conversely, a longer turnaround time of hours to days is acceptable for elective indications, allowing for the use of assays that measure DOAC levels (Table 2), even if they need to be sent out to a reference laboratory.

\section{Emergent indications}

\section{Serious bleeding}

Patients on DOACs may experience serious or life-threatening bleeding. In such situations, the clinician must make a rapid determination about whether to use a reversal agent. DOAC laboratory assessment can be a useful tool in guiding this decision [17]. If the result of a quantitative assay can be obtained quickly, a drug level $>50 \mathrm{ng} / \mathrm{ml}$ may be used to justify the administration of a reversal agent, consistent with ISTH guidance [16]. More often, a quantitative assay will not be available with sufficiently rapid turnaround and the clinician will need to rely on a screening assay. In a patient taking dabigatran, a normal TT or DOASENSE' would be justification for withholding a reversal agent. Similarly, reversal would not be warranted 
in a patient taking an oral factor Xa inhibitor with a negative DOASENSE ${ }^{\mathrm{TM}}$ or a heparin anti-Xa level below the lower limit of quantification (Table 2).

Incomplete or impermanent reversal has been reported with the DOAC reversal agents, idarucizumab and andexanet alfa. Uncommonly, repeat dosing of a reversal agent may be considered. In such cases, a quantitative assay to measure drug levels may be useful for determining the need for re-dosing [18].

Measurement of a DOAC level in a bleeding patient may also be useful for excluding drug concentrations above the expected range (Table 3), which could be due to accidental or intentional overdose or to a condition resulting in DOAC bioaccumulation (e.g. low body weight, renal or hepatic dysfunction, certain drug-drug interactions).

\section{Urgent surgery}

The Perioperative Anticoagulation Use for Surgery Evaluation (PAUSE) study showed that DOAC levels generally do not need to be measured before elective procedures. Moreover, some procedures can be performed safely without interruption of anticoagulation [19, 20]. Nevertheless, DOAC laboratory assessment may be helpful prior to certain unplanned, urgent surgeries [19], especially if there is consideration for delaying the surgery or administering a reversal agent [17].

If the result of a quantitative assay can be obtained quickly, a drug level $>30 \mathrm{ng} / \mathrm{ml}$ may be used to justify postponement of a high bleeding risk procedure or administration of a reversal agent, consistent with ISTH guidance [16]. If a quantitative assay is not available with a sufficiently rapid turnaround, the clinician may need to rely on a screening assay. In a patient taking dabigatran, a normal TT or DOASENSE ${ }^{\text {TM }}$ would justify withholding a reversal agent [17]. Similarly, reversal would not be warranted in a patient taking an oral factor Xa inhibitor with a negative DOASENSE ${ }^{\mathrm{TM}}$ or a heparin anti-Xa level below the lower limit of quantification (Table 2).

\section{Acute ischemic stroke, consideration of thrombolysis}

The American Heart Association/American Stroke Association 2018 guideline recommends against intravenous thrombolysis (IVT) in patients on DOACs who have taken their last dose within the previous 48 hours and have laboratory evidence of residual anticoagulant effect [21]. However, a recent expert review highlights that using time since the last dose of anticoagulation as a surrogate for DOAC activity is not always reliable due to pharmacokinetic variability among patients [22]. The authors recommend proceeding with IVT if at least 48 hours have elapsed since the last DOAC dose and the creatinine clearance is $>50 \mathrm{ml} / \mathrm{min}$. If the patient does not meet one or both criteria, DOAC laboratory assessment is recommended. For patients on dabigatran, IVT is only recommended if the dabigatran level is $<30 \mathrm{ng} / \mathrm{ml}$ or the TT is normal. For patients on an oral factor Xa inhibitor, IVT is recommended if the drug level is $<30 \mathrm{ng} / \mathrm{ml}$ and may be considered if the drug level is $30-100 \mathrm{ng} / \mathrm{ml}$ [22]. Clinical outcome data validating these recommendations are needed.

Measurement of a DOAC level in a DOAC-treated patient with stroke or other thromboembolic events may also be useful for excluding drug concentrations below the expected range (Table 3 ), which could be due to a condition resulting in low DOAC levels (e.g. high body weight, renal hyperfunction, certain drug-drug interactions, gastrointestinal malabsorption) or to non-adherence. It should be noted, however, that a DOAC level only indicates whether the patient took the prescribed drug in the last 12 to 24 hours. Owing to the short half-life of the DOACs (Table 1), the measurement of DOAC levels is not a useful tool for assessing longer-term adherence.

\section{Elective indications}

\section{Extremes of body weight}

Patients with extremes of body weight (e.g. $<50 \mathrm{~kg}$ or $>120 \mathrm{~kg}$ ) had very limited representation in the pivotal trials that led to the approval of the DOACs. There is a theoretical concern that high body weight could be associated with subtherapeutic drug levels whereas low body weight could be associated with DOAC bioaccumulation. Based on these concerns, the ISTH has suggested that DOACs be avoided in patients weighing $>120 \mathrm{~kg}$ or with a body mass index $>40 \mathrm{~kg} / \mathrm{m}^{2}$. If DOACs are to be used in this population, the ISTH recommends measuring DOAC peak and trough levels to ensure that they fall within the expected range (Table 3) [23]. The ISTH has not offered guidance for patients with low body weight.

In spite of these cautions, clinical outcome evidence in patients with extremes of body weight, particularly high body weight, has been largely reassuring. In a meta-analysis and systematic review of 11 randomized controlled trials of DOACs in non-valvular atrial fibrillation and VTE, patients with high body weight did not have a greater risk of thrombosis than those with non-high body weight. Interestingly, patients with low body weight had an increased thrombotic risk, but not an increased bleeding risk compared with non-low bodyweight individuals [24]. In a retrospective analysis of 18,147 patients with VTE treated with DOACs, 6-month readmission for recurrent VTE was not increased in the $13 \%$ of patients weighing $>120 \mathrm{~kg}$ [25]. Another 5 -year retrospective study found no difference in VTE recurrence in 133 patients weighing $\geq 120 \mathrm{~kg}$ compared to $1063 \mathrm{pa}$ tients weighing $<120 \mathrm{~kg}(0.8 \%$ vs $1.1 \%$; OR, $0.66 ; 95 \% \mathrm{Cl}$, 0.09-5.14; $P=0.69$ ) [26]. Apixaban for Reduction in Stroke and Other Thromboembolic Events in Atrial Fibrillation ( $n=18,201)$, a randomized trial comparing apixaban with warfarin for the prevention of stroke in patients with atrial fibrillation, included 1,985 (10.9\%) patients weighing $\leq 60 \mathrm{~kg}$ group and 982 (5.4\%) patients weighing $>120 \mathrm{~kg}$. Apixaban was found to be efficacious and safe in both groups [27]. 
Although these studies suggest that DOAC laboratory assessment may not be necessary in most adults with low or high body weight, they included few patients weighing $<50 \mathrm{~kg}$ or $>150 \mathrm{~kg}$. Thus, it may be reasonable to consider the measurement of steady-state trough and peak levels in such patients to confirm they are within the expected range (Table 3 ). If levels are outside the expected range, transition to a VKA should be considered.

\section{Renal hypo- or hyperfunction}

All 4 DOACs are partially cleared by the kidneys, with dabigatran being the most reliant $(80 \%)$ on renal elimination (Table 1) [28]. DOAC levels are therefore inversely related to renal function. For example, in the pivotal trial of dabigatran for atrial fibrillation, subjects with a creatinine clearance of $30-50 \mathrm{ml} / \mathrm{min}$ had a 2.29 -fold greater dabigatran trough concentration than those with creatinine clearance $\geq 80 \mathrm{ml} / \mathrm{min}$ [15]. Conversely, edoxaban was shown to be less efficacious in patients with atrial fibrillation and very robust renal function (i.e. creatinine clearance $>95 \mathrm{ml} / \mathrm{min}$ ), presumably due to lower plasma drug concentrations [28].

Dosing recommendations in the US FDA labels reflect the importance of renal function on DOAC levels and clinical outcomes [29-32]. Among patients with atrial fibrillation, edoxaban is contraindicated in patients with a creatinine clearance $>95 \mathrm{ml} / \mathrm{min}$. Dose-reduction is advised for edoxaban and rivaroxaban if the creatinine clearance is $15-50 \mathrm{ml} / \mathrm{min}$, for dabigatran if the creatinine clearance is $15-30 \mathrm{ml} / \mathrm{min}$, and for apixaban if the patient has at least two of three features (creatinine $\geq 1.5 \mathrm{ml} / \mathrm{min}$, age $\geq 80$, or weight $\leq 60 \mathrm{~kg}$ ) that could contribute to reduced creatinine clearance [33].

While these dosing recommendations apply to patients with chronic kidney disease stages I through IV, there is greater controversy about anticoagulant selection and dosing in patients with stage $\mathrm{V}$ chronic kidney disease (creatinine clearance $<15 \mathrm{ml} / \mathrm{min}$ or on dialysis) as well as in patients with rapidly changing renal function. In such patients, measurement of DOAC peak and trough levels may be useful in guiding management. For example, identification of levels above the on-therapy range (Table 3) may justify changing to a different DOAC that is less reliant on renal clearance, to an entirely different class of anticoagulant such as a VKA, or discontinuation of anticoagulation altogether depending on the clinical context and indication.

\section{Liver disease}

All 4 DOACs are variably metabolized by the liver with apixaban being the most reliant (75\%) and dabigatran the least reliant (20\%) on hepatic metabolism [34] Moreover, decreased albumin synthesis in patients with liver disease may affect levels of the free drug depending on the degree to which each agent is protein-bound (Table 1).

Evidence on the use of DOACs in patients with moderate or severe liver disease is limited. Such patients were excluded from the pivotal clinical trials. Small retrospective studies have been reported [35-37].

The US FDA recommends using the Child-Pugh score to guide dosing. Dose adjustment is not needed for any of the DOACs in patients with Child-Pugh class A (mild hepatic impairment). Caution or avoidance is advised for apixaban, edoxaban, and rivaroxaban in patients with moderate (Class B) or severe (Class C) liver disease [29-32, 34]. Prescribing instructions differ in other jurisdictions including Europe and Canada.

If a DOAC is to be used in a patient with moderate or severe liver disease, steady-state peak and trough levels may be useful for confirming that drug concentrations are within the expected range (Table 3 ). If a level is above the on-therapy range, it may be advisable to change to a different DOAC that is less reliant on the liver for its metabolism or to change to a different class of anticoagulant (e.g. VKA, low molecular weight heparin).

\section{Suspected drug-drug interactions}

An important advantage of DOACs over VKAs is that DOACs have fewer drug-drug interactions. Nevertheless, DOACs are substrates of cytochrome p450 (particularly CYP3A4) as well as p-glycoprotein (P-gp) and drugs that inhibit or induce these systems may affect plasma DOAC concentrations $[33,38,39]$. CYP3A4 is important for metabolizing apixaban (20\%-25\%) and rivaroxaban (50\%), but not dabigatran or edoxaban. Dabigatran and edoxaban are major substrates and apixaban and rivaroxaban are minor substrates of P-gp [39] (Table 1).

Drug interactions can affect DOAC levels and, in turn, may influence clinical outcomes. A study of the Taiwanese national insurance database showed that concurrent use of dabigatran, rivaroxaban, or apixaban with amiodarone, fluconazole, rifampin, or phenytoin was associated with increased major bleeding $[39,40]$. The FDA labels for DOACs acknowledge the risk posed by drug-drug interactions by recommending avoidance or dose-reduction with concomitant use of certain medications [29-32].

In addition to avoidance or dose-reduction, measurement of drug levels may serve as a useful strategy for guiding management. Steady-state peak and trough levels in the expected range (Table 3 ) may provide reassurance that it is safe to continue a given drug combination. Conversely, a drug level outside of the expected range may suggest the need to adjust the dose of the DOAC, change to another DOAC that is less likely to have a potent interaction with the concomitant medication, change to a different class of anticoagulant (e.g. VKA), or stop the concomitant medication.

\section{Suspected gastrointestinal malabsorption}

A number of conditions could potentially be associated with malabsorption of DOACs including bariatric surgery, short-gut syndrome, inflammatory bowel disease, and other disorders of the gastrointestinal tract. 
In a study of 9 patients who had undergone roux-en-y gastric bypass, the median peak dabigatran concentration was only $34.6 \mathrm{ng} / \mathrm{ml}$, well below the expected range (Table 3) [41]. Another study compared peak DOAC levels in 18 bariatric surgery patients and 18 controls. Five (28\%) patients in the bariatric group and 0 in the control group had peak levels below the expected range. All 5 patients with low levels were taking rivaroxaban. Other pharmacokinetic studies suggest reduced rivaroxaban absorption after sleeve gastrectomy or gastric banding [42].

The aforementioned pharmacokinetic evidence notwithstanding, it remains uncertain whether reduced DOAC levels in bariatric surgery patients translate to inferior outcomes. A recent observational study of patients on oral anticoagulation for atrial fibrillation compared outcomes in 1,673 bariatric surgery patients with 155,619 non-bariatric patients. The incidence of ischemic stroke/systemic embolism ( 0.83 vs 1.32 per 100 person years; HR, $0.62,95 \%$ $\mathrm{Cl}, 0.31-1.22 ; P=0.17$ ) and major bleeding (5.30 vs 4.87 per 100 person years; $\mathrm{HR}, 1.05,95 \% \mathrm{Cl}, 0.80-1.37 ; P=0.73$ ) was similar between the 2 groups [43].

There is scant information regarding DOAC absorption in other conditions. One small study demonstrated potentially reduced dabigatran and rivaroxaban levels in patients with short-gut syndrome [44]. We are not aware of evidence on DOAC levels in other malabsorptive disorders including inflammatory bowel disease, celiac disease, or small bowel bacterial overgrowth.

If a patient with suspected gastrointestinal malabsorption is treated with a DOAC, it may be reasonable to measure steady-state peak and trough levels. If the levels are below the expected range (Table 3), suggestive of DOAC malabsorption, a change to a different anticoagulant such as a VKA may be warranted [45].

\section{CONCLUSION}

Although DOACs do not require routine laboratory monitoring of anticoagulant level, there are special circumstances in which laboratory assessment may be helpful in guiding management. Indications for laboratory assessment of DOACs may be divided into emergent (serious bleeding, urgent surgery, acute ischemic stroke) and elective (extremes of bodyweight, renal hypo- or hyperfunction, liver disease, suspected drug-drug interaction, suspected gastrointestinal malabsorption).

Our approach to patients with an emergent indication for laboratory assessment is summarized in Figure 1. If available with sufficiently rapid turnaround time, a randomly timed quantitative assay that measures plasma DOAC levels should be ordered. If a quantitative assay is not available,

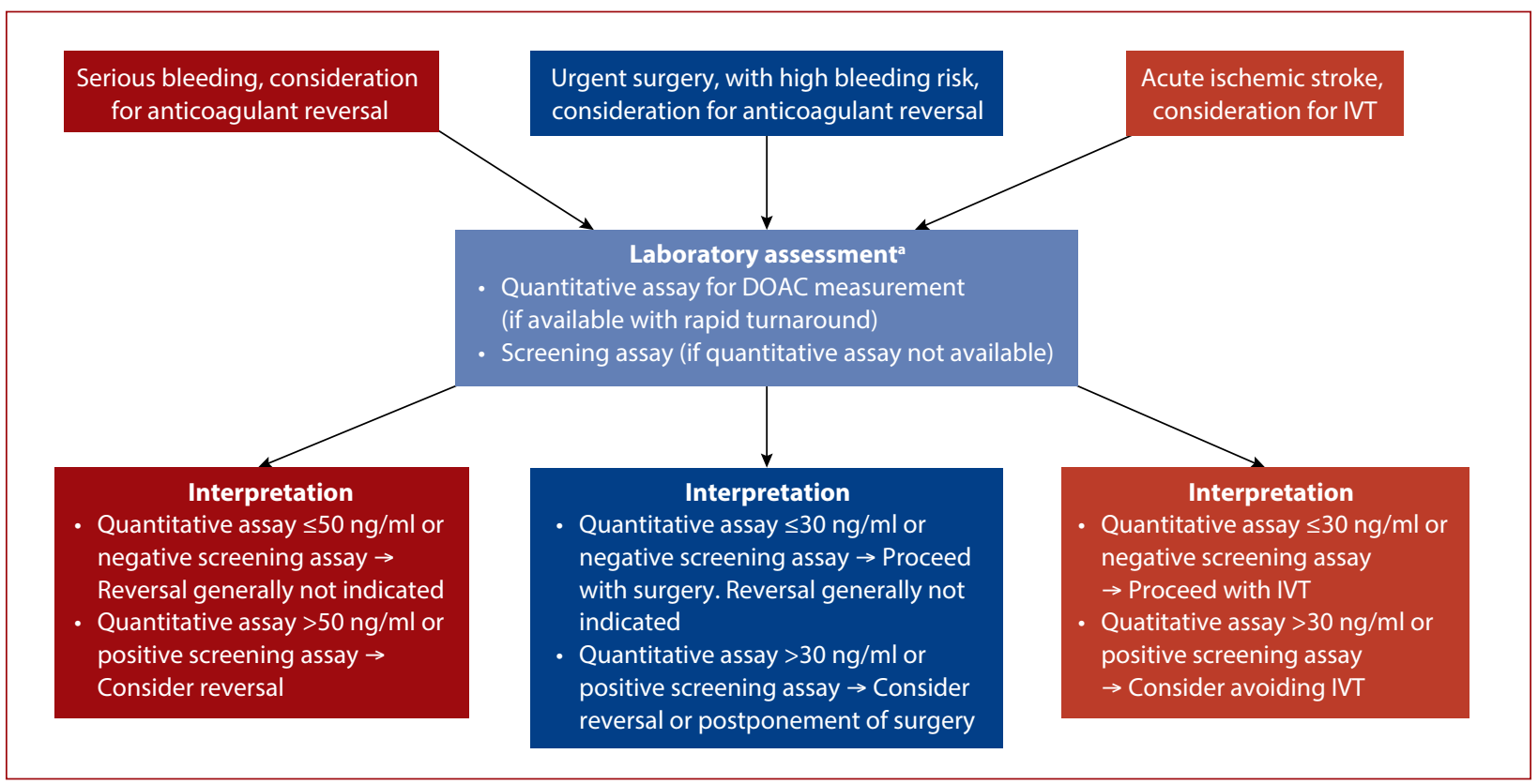

Figure 1. Approach to the patient with an emergent indication for direct oral anticoagulants (DOAC) laboratory assessment. Emergent indications for DOAC laboratory assessment include serious bleeding or urgent surgery with consideration for anticoagulant reversal or acute ischemic stroke with consideration for IVT. In a patient with an emergent indication for DOAC laboratory assessment, a randomly timed DOAC level should be measured using a quantitative assay. If a quantitative assay with sufficiently rapid turnaround time is not available, a screening assay should be used. In patients with serious bleeding and a DOAC level $\leq 50 \mathrm{ng} / \mathrm{ml}$ or a negative screening assay, anticoagulant reversal is generally not warranted. However, if the DOAC level is $>50 \mathrm{ng} / \mathrm{ml}$ or a screening assay is positive, reversal should be considered depending on the type and severity of the bleed [16]. In patients who require urgent surgery with high bleeding risk, reversal is generally not warranted if the DOAC level is $\leq 30 \mathrm{ng} / \mathrm{ml}$ or a screening assay is negative. However, if the DOAC level is $>30 \mathrm{ng} / \mathrm{ml}$ or a screening assay is positive, reversal or postponement of surgery should be considered depending on the nature and urgency of the surgery [16]. In patients with acute ischemic stroke and a DOAC level $\leq 30 \mathrm{ng} / \mathrm{ml}$ or a negative screening assay, IVT is likely to be safe. The maximum DOAC level at which IVT is safe is unknown. We suggest avoiding IVT if the DOAC level is $>30 \mathrm{ng} / \mathrm{ml}$ or a screening assay is positive [21, 22]. aSee Table 2 for a list of assays that may be used for laboratory assessment of DOACs.

Abbreviations: IVT, intravenous thrombolysis 


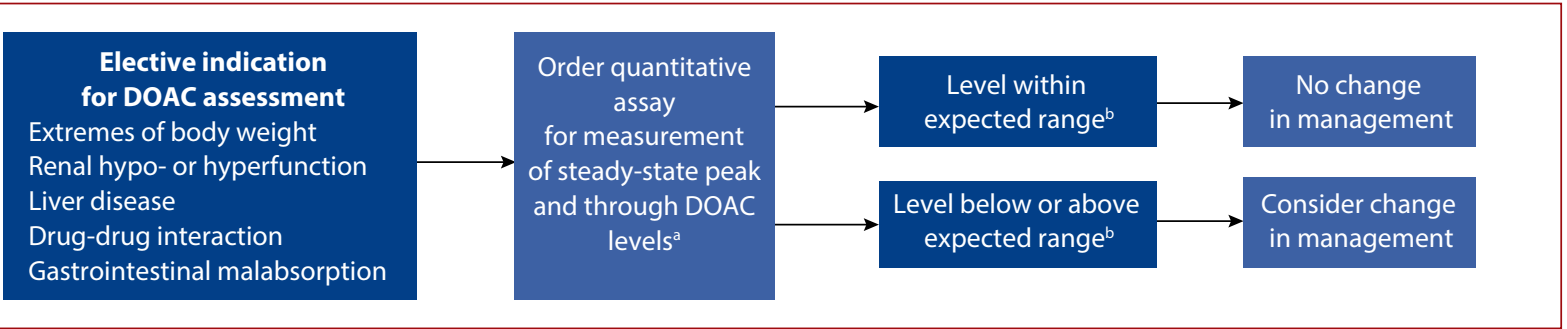

Figure 2. Approach to the patient with an elective indication for direct oral anticoagulants (DOAC) laboratory assessment. In a patient with an elective indication for DOAC laboratory assessment, steady-state peak and trough levels should be measured using a quantitative assay. Levels within the expected range support continuation of present management. A level outside the expected range should prompt consideration of a change in management. Depending on the clinical context, a change in management may include adjusting the DOAC dose, changing to a different DOAC, or changing to an anticoagulant of a different class (see text for further details). aSee Table 2 for a list of assays

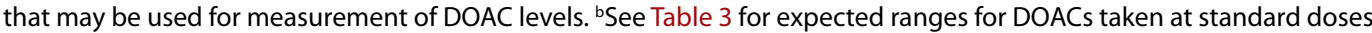

a screening assay should be requested (Table 2). Threshold DOAC levels above which anticoagulant reversal or avoidance of IVT is warranted have been proposed [16, 21, 22] and are listed in Figure 1. These thresholds are based largely on expert opinion. Clinical outcomes research is needed to refine and validate these thresholds. Development of simple, rapid, point-of-care quantitative assays is also needed so that measurement of plasma DOAC levels for emergent indications can be made accessible to a greater number of patients.

Our approach to patients with an elective indication for laboratory assessment is depicted in Figure 2. Steady-state peak and trough plasma DOAC levels should be measured using a quantitative assay (Table 2). Levels that fall within the expected range (Table 3 ) support the continuation of current management. Levels that fall outside the expected range should prompt consideration of a change in management, which may include adjustment of the DOAC dose, changing to a different DOAC, or changing to a different class of anticoagulant, depending on the clinical scenario. Further research is needed to better understand the relationship between plasma DOAC levels and clinical outcomes.

While the development of improved assays and additional evidence linking DOAC levels and clinical outcomes is eagerly awaited, clinicians should be aware that laboratory assessment of DOACs using currently available methods may be used to guide the management of their patients in special situations.

\section{Article information}

Conflict of interest: AC has served as a consultant for Synergy, has received authorship royalties from UpToDate, and his institution has received research support on his behalf from Alexion, Bayer, Novartis, Novo Nordisk, Pfizer, Sanofi, Spark, and Takeda. IJA has no conflicts to declare.

Open access: This article is available in open access under Creative Common Attribution-Non-Commercial-No Derivatives 4.0 International (CC BY-NC-ND 4.0) license, allowing to download articles and share them with others as long as they credit the authors and the publisher, but without permission to change them in any way or use them commercially. For commercial use, please contact the journal office at kardiologiapolska@ptkardio.pl.
How to cite: Akpan IJ, Cuker A. Laboratory assessment of the direct oral anticoagulants: who can benefit? Kardiol Pol. 2021;79(6):622-630, doi: 10.33963/KP.a2021.0021.

\section{REFERENCES}

1. Zhu J, Alexander GC, Nazarian $\mathrm{SN}$, et al. Trends and variation in oral anticoagulant choice in patients with atrial fibrillation, 2010-2017. Pharmacotherapy. 2018; 38(9): 907-920, doi: 10.1002/phar.2158, indexed in Pubmed: 29920705.

2. Lip GYH, Banerjee A, Boriani G, et al. Antithrombotic therapy for atrial fibrillation: CHEST guideline and expert panel report. Chest. 2018; 154(5): 1121-1201, doi: 10.1016/j.chest.2018.07.040, indexed in Pubmed: 30144419.

3. van Es N, Coppens M, Schulman S, et al. Direct oral anticoagulants compared with vitamin $\mathrm{K}$ antagonists for acute venous thromboembolism: evidence from phase 3 trials. Blood. 2014; 124(12): 1968-1975, doi: 10.1182/blood-2014-04-571232, indexed in Pubmed: 24963045.

4. López-López JA, Sterne JAC, Thom HHZ, et al. Oral anticoagulants for prevention of stroke in atrial fibrillation: systematic review, network meta-analysis, and cost effectiveness analysis. BMJ. 2017; 359: j5058, doi: 10.1136/bmj.j5058, indexed in Pubmed: 29183961.

5. Patel MR, Mahaffey KW, Garg J, et al. ROCKET AF Investigators. Rivaroxaban versus warfarin in nonvalvular atrial fibrillation. N Engl J Med. 2011; 365(10): 883-891, doi: 10.1056/NEJMoa1009638, indexed in Pubmed: 21830957.

6. Held C, Hylek EM, Alexander JH, et al. Clinical outcomes and management associated with major bleeding in patients with atrial fibrillation treated with apixaban or warfarin: insights from the ARISTOTLE trial. Eur Heart J. 2015; 36(20): 1264-1272, doi: 10.1093/eurheartj/ehu463.

7. Giugliano RP, Ruff CT, Wiviott SD, et al. Mortality in patients with atrial fibrillation randomized to edoxaban or warfarin: insights from the ENGAGE AF-TIMI 48 trial. Am J Med. 2016; 129(8):850-857.e2, doi: 10.1016/j. amjmed.2016.02.028, indexed in Pubmed: 26994510.

8. van Gorp RH, Schurgers LJ. New insights into the pros and cons of the clinical use of vitamin K antagonists (VKAs) versus direct oral anticoagulants (doacs). Nutrients. 2015; 7(11): 9538-9557, doi: 10.3390/nu7115479, indexed in Pubmed: 26593943.

9. Bauer KA. Pros and cons of new oral anticoagulants. Hematology Am Soc Hematol Educ Program. 2013; 2013(1):464-470, doi: 10.1182/asheducation-2013.1.464.

10. Cuker A. Laboratory measurement of the non-vitamin $\mathrm{K}$ antagonist oral anticoagulants: selecting the optimal assay based on drug, assay availability, and clinical indication. J Thromb Thrombolysis. 2016; 41(2): 241-247, doi: 10.1007/s11239-015-1282-7, indexed in Pubmed: 26386967.

11. Gosselin RC, Adcock DM, Bates SM, et al. International Council for Standardization in Haematology (ICSH) recommendations for laboratory measurement of direct oral anticoagulants. Thromb Haemost. 2018; 118(3): 437-450, doi: 10.1055/s-0038-1627480, indexed in Pubmed: 29433148.

12. Samuelson BT, Cuker A, Siegal DM, et al. Laboratory assessment of the anticoagulant activity of direct oral anticoagulants: a systematic review. 
Chest. 2017; 151(1): 127-138, doi: 10.1016/j.chest.2016.08.1462, indexed in Pubmed: 27637548.

13. Tripodi A, Ageno W, Ciaccio M, et al. Position paper on laboratory testing for patients on direct oral anticoagulants. A consensus document from the SISET, FCSA, sibioc and sipmel. Blood Transfus. 2018; 16(5): 462-470, doi: 10.2450/2017.0124-17, indexed in Pubmed: 29106357.

14. Patel JP, Byrne RA, Patel RK, et al. Progress in the monitoring of direct oral anticoagulant therapy. Br J Haematol. 2019; 184(6): 912-924, doi: 10.1111/bjh.15756, indexed in Pubmed: 30697708.

15. Reilly PA, Lehr T, Haertter S, et al. RE-LY Investigators. The effect of dabigatran plasma concentrations and patient characteristics on the frequency of ischemic stroke and major bleeding in atrial fibrillation patients: the RE-LYTrial (Randomized Evaluation of Long-Term Anticoagulation Therapy). J Am Coll Cardiol. 2014; 63(4): 321-328, doi: 10.1016/j. jacc.2013.07.104, indexed in Pubmed: 24076487.

16. Levy JH, Ageno W, Chan NC, et al. Subcommittee on Control of Anticoagulation. When and how to use antidotes for the reversal of direct oral anticoagulants: guidance from the SSC of the ISTH. J Thromb Haemost. 2016; 14(3): 623-627, doi: 10.1111/jth.13227, indexed in Pubmed: 26911798.

17. Crowther $M$, Cuker A. How can we reverse bleeding in patients on direct oral anticoagulants? Kardiol Pol. 2019; 77(1): 3-11, doi: 10.5603/KP.a2018.0197, indexed in Pubmed: 30338501.

18. Simon A, Domanovits $\mathrm{H}, \mathrm{Ay} \mathrm{C}$, et al. The recommended dose of idarucizumab may not always be sufficient for sustained reversal of dabigatran. J Thromb Haemost. 2017; 15(7):1317-1321, doi: 10.1111/jth.13706, indexed in Pubmed: 28426914.

19. Douketis J, Spyropoulos A, Duncan J, et al. Perioperative management of patients with atrial fibrillation receiving a direct oral anticoagulant. JAMA Intern Med. 2019; 179(11): 1469-1478, doi: 10.1001/jamainternmed.2019.2431, indexed in Pubmed: 31380891.

20. Cuker A, Burnett A, Triller D, et al. Reversal of direct oral anticoagulants: Guidance from the Anticoagulation Forum. Am J Hematol. 2019; 94(6): 697-709, doi: 10.1002/ajh.25475, indexed in Pubmed: 30916798.

21. Powers W, Rabinstein A, Ackerson T, et al. 2018 guidelines for the early management of patients with acute ischemic stroke: a guideline for healthcare professionals from the American Heart Association/American Stroke Association. Stroke. 2018; 49(3): e46-e99, doi: $10.1161 /$ str.0000000000000158.

22. Seiffge DJ, Meinel T, Purrucker JC, et al. Recanalisation therapies for acute ischaemic stroke in patients on direct oral anticoagulants. J Neurol Neurosurg Psychiatry. 2021; 92(5): 534-541, doi: 10.1136/jnnp-2020-325456, indexed in Pubmed: 33542084.

23. Martin K, Beyer-Westendorf J, Davidson BL, et al. Use of the direct oral anticoagulants in obese patients: guidance from the SSC of the ISTH. J Thromb Haemost. 2016; 14(6): 1308-1313, doi: 10.1111/jth.13323, indexed in Pubmed: 27299806.

24. Boonyawat K, Caron F, Li A, et al. Association of body weight with efficacy and safety outcomes in phase III randomized controlled trials of direct oral anticoagulants: a systematic review and meta-analysis. J Thromb Haemost. 2017; 15(7): 1322-1333, doi: 10.1111/jth.13701, indexed in Pubmed: 28407368.

25. Younis M, Elkaryoni A, Williams GW, et al. The use of direct oral anticoagulants in the management of venous thromboembolism in patients with obesity. Cureus. 2020; 12(8): e10006, doi: 10.7759/cureus.10006, indexed in Pubmed: 32983703.

26. Aloi KG, Fierro JJ, Stein BJ, et al. Investigation of direct-acting oral anticoagulants and the incidence of venous thromboembolism in patients weighing $\geq 120 \mathrm{~kg}$ compared to patients weighing $<120 \mathrm{~kg}$. J Pharm Pract. 2021; 34(1): 64-69, doi: 10.1177/0897190019854578, indexed in Pubmed: 31238775.

27. Hohnloser $\mathrm{SH}$, Fudim M, Alexander $\mathrm{JH}$, et al. Efficacy and safety of apixaban versus warfarin in patients with atrial fibrillation and extremes in body weight. Circulation. 2019; 139(20):2292-2300, doi: 10.1161/CIRCULATIONAHA.118.037955, indexed in Pubmed: 30773022

28. Steffel J, Verhamme P, Potpara TS, et al. ESC Scientific Document Group. The 2018 European Heart Rhythm Association Practical Guide on the use of non-vitamin $\mathrm{K}$ antagonist oral anticoagulants in patients with atrial fibrillation. Eur Heart J. 2018; 39(16): 1330-1393, doi: 10.1093/eurheartj/ehy136, indexed in Pubmed: 29562325.
29. FoodandDrug Administration. Pradaxa — prescribing information. https:// www.accessdata.fda.gov/drugsatfda_docs/label/2015/022512s028lbl.pdf (April 27, 2021).

30. Food and Drug Administration. Xarelto - prescribing information. ttp:// www.accessdata.fda.gov/drugsatfda_docs/label/2011/202439s001lbl. pdf (April 27, 2021).

31. Food and Drug Administration. Eliquis — prescribing information. https:// www.accessdata.fda.gov/drugsatfda_docs/label/2012/202155s000lbl. pdf (April 27, 2021).

32. Food and Drug Administration. Edoxaban - prescribing information. https://www.accessdata.fda.gov/drugsatfda_docs/label/2015/206316lbl. pdf (April 27, 2021).

33. Chen A, Stecker E, A Warden B. Direct oral anticoagulant use: a practical guide to common clinical challenges. J Am Heart Assoc. 2020; 9(13): e017559, doi: 10.1161/JAHA.120.017559, indexed in Pubmed: 32538234.

34. Qamar A, Vaduganathan M, Greenberger NJ, et al. Oral anticoagulation in patients with liver disease. J Am Coll Cardiol. 2018; 71(19): 2162-2175, doi: 10.1016/j.jacc.2018.03.023, indexed in Pubmed: 29747837.

35. Hum J, Shatzel JJ, Jou JH, et al. The efficacy and safety of direct oral anticoagulants vs traditional anticoagulants in cirrhosis. Eur J Haematol. 2017; 98(4): 393-397, doi: 10.1111/ejh.12844, indexed in Pubmed: 28009449.

36. Huang ZC, Li CQ, Liu XY, et al. Efficacy and safety of direct oral anticoagulants in patients with atrial fibrillation and liver disease: a meta-analysis and systematic review. Cardiovasc Drugs Ther. 2020 [Epub ahead of print], doi: 10.1007/s10557-020-07065-y, indexed in Pubmed: 32880804.

37. Hoolwerf EW, Kraaijpoel N, Büller HR, et al. Direct oral anticoagulants in patients with liver cirrhosis: a systematic review. Thromb Res. 2018; 170: 102-108, doi: 10.1016/j.thromres.2018.08.011, indexed in Pubmed: 30153564.

38. Bellesini M, Bianchin M, Corradi C, et al. Drug-drug interactions between direct oral anticoagulants and hepatitis $C$ direct-acting antiviral agents: looking for evidence through a systematic review. Clin Drug Investig. 2020; 40(11): 1001-1008, doi: 10.1007/s40261-020-00962-y, indexed in Pubmed: 32809123.

39. Wiggins BS, Dixon DL, Neyens RR, et al. Select drug-drug interactions with direct oral anticoagulants: JACC review topic of the week. J Am Coll Cardiol. 2020; 75(11): 1341-1350, doi: 10.1016/j.jacc.2019.12.068, indexed in Pubmed: 32192661.

40. Chang SH, Chou IJ, Yeh YH, et al. Association between use of non-vitamin $\mathrm{K}$ oral anticoagulants with and without concurrent medications and risk of major bleeding in nonvalvular atrial fibrillation. JAMA. 2017; 318(13): 1250-1259, doi: 10.1001/jama.2017.13883, indexed in Pubmed: 28973247.

41. Grainger B, Holloway R, Merriman E, et al. Evidence of impaired dabigatran absorption following laparoscopic Roux-en-Y gastric bypass surgery: the Auckland regional experience (2011-2018). Br J Haematol. 2020; 191(2): e67-e69, doi: 10.1111/bjh.17004, indexed in Pubmed: 32720718.

42. Rottenstreich A, Barkai A, Arad A, et al. The effect of bariatric surgery on direct-acting oral anticoagulant drug levels. Thromb Res. 2018; 163: 190195, doi: 10.1016/j.thromres.2017.11.006, indexed in Pubmed: 29157916.

43. Hendricks AK, Zieminski JJ, Yao X, et al. Safety and efficacy of oral anticoagulants for atrial fibrillation in patients after bariatric surgery. Am J Cardiol. 2020; 136: 76-80, doi: 10.1016/j.amjcard.2020.09.020, indexed in Pubmed: 32941819.

44. Cheung YW, Barco S, Mathôt RAA, et al. Pharmacokinetics of dabigatran etexilate and rivaroxaban in patients with short bowel syndrome requiring parenteral nutrition: The PDER PAN study. Thromb Res. 2017; 160: 76-82, doi: 10.1016/j.thromres.2017.10.025, indexed in Pubmed: 29127863.

45. Martin KA, Lee CR, Farrell TM, et al. Oral anticoagulant use after bariatric surgery: a literature review and clinical guidance. Am J Med. 2017; 130(5): 517-524, doi: 10.1016/j.amjmed.2016.12.033, indexed in Pubmed: 28159600.

46. Ganetsky M, Babu KM, Salhanick SD, et al. Dabigatran: review of pharmacology and management of bleeding complications of this novel oral anticoagulant. J Med Toxicol. 2011; 7(4): 281-287, doi: 10.1007/s13181011-0178-y, indexed in Pubmed: 21887485.

47. Hankey GJ, Eikelboom JW. Dabigatran etexilate: a new oral thrombin inhibitor. Circulation. 2011; 123(13): 1436-1450, doi: 10.1161/CIRCULATIONAHA.110.004424, indexed in Pubmed: 21464059. 
48. Mueck W, Stampfuss J, Kubitza D, et al. Clinical pharmacokinetic and pharmacodynamic profile of rivaroxaban. Clin Pharmacokinet. 2014; 53(1): 1-16, doi: 10.1007/s40262-013-0100-7, indexed in Pubmed: 23999929.

49. Stampfuss J, Kubitza D, Becka M, et al. The effect of food on the absorption and pharmacokinetics of rivaroxaban. Int J Clin Pharmacol Ther. 2013; 51(7): 549-561, doi: 10.5414/CP201812, indexed in Pubmed: 23458226.

50. Byon W, Garonzik S, Boyd RA, et al. Apixaban: a clinical pharmacokinetic and pharmacodynamic review. Clin Pharmacokinet. 2019; 58(10): $1265-$ 1279, doi: 10.1007/s40262-019-00775-z, indexed in Pubmed: 31089975.

51. Kubli KA, Snead JA, Cheng-Lai A. Edoxaban: a novel factor xa inhibitor for the management of non-valvular atrial fibrillation and venous thromboembolism. Cardiol Rev. 2016; 24(4): 205-210, doi: 10.1097/CRD.0000000000000104, indexed in Pubmed: 26991962.

52. Ezekowitz MD, Reilly PA, Nehmiz G, et al. Dabigatran with or without concomitant aspirin compared with warfarin alone in patients with nonvalvular atrial fibrillation (PETRO Study). Am J Cardiol. 2007; 100(9): 1419-1426, doi: 10.1016/j.amjcard.2007.06.034, indexed in Pubmed: 17950801.

53. Hindricks G, Potpara T, Dagres N, et al. ESC Scientific Document Group. 2020 ESC Guidelines for the diagnosis and management of atrial fibril- lation developed in collaboration with the European Association for Cardio-Thoracic Surgery (EACTS). Eur Heart J. 2021; 42(5): 373-498, doi: 10.1093/eurheartj/ehaa612, indexed in Pubmed: 32860505.

54. van Ryn J, Stangier J, Haertter S, et al. Dabigatran etexilate - a novel, reversible, oral direct thrombin inhibitor: interpretation of coagulation assays and reversal of anticoagulant activity. Thromb Haemost. 2010; 103(6): 1116-1127, doi: 10.1160/TH09-11-0758, indexed in Pubmed: 20352166.

55. Burghaus R, Coboeken K, Gaub T, et al. Evaluation of the efficacy and safety of rivaroxaban using a computer model for blood coagulation. PLoSOne. 2011;6(4):e17626, doi: 10.1371/journal.pone.0017626, indexed in Pubmed: 21526168.

56. Frost C, Nepal S, Wang J, et al. Safety, pharmacokinetics and pharmacodynamics of multiple oral doses of apixaban, a factor Xa inhibitor, in healthy subjects. Br J Clin Pharmacol. 2013; 76(5): 776-786, doi: 10.1111/bcp.12106, indexed in Pubmed: 23451769.

57. Cuker A, Husseinzadeh H. Laboratory measurement of the anticoagulant activity of edoxaban: a systematic review. J Thromb Thrombolysis. 2015; 39(3): 288-294, doi: 10.1007/s11239-015-1185-7, indexed in Pubmed: 25669624. 